\title{
Viabilidade de hastes porta-borbulhas de citros em diferentes estádios de desenvolvimento e períodos de armazenamento
}

\author{
Dalmo Lopes de Siqueira ${ }^{1}$, Luiz Carlos Chamhum Salomão ${ }^{1}$, Luiz Alexandre Peternelli², Dierlei dos Santos ${ }^{3}$, \\ Sebastião Antônio Gomes ${ }^{4}$
}

\section{RESUMO}

Borbulhas de citros requerem condições especiais de armazenamento para que, após determinado período de conservação ainda mantenham sua viabilidade para a enxertia. Este trabalho objetivou avaliar o efeito da idade das hastes porta-borbulhas de dois cultivares de laranja doce e do período de armazenamento sobre a viabilidade das borbulhas para enxertia. Utilizou-se o delineamento em blocos casualizados, em esquema fatorial 2 x 2 x 3 , avaliando-se dois cultivares de laranjeira ('Baianinha’ e 'Pêra Rio'), três períodos de armazenamento (0, 60 e 120 dias), hastes de três idades (100, 120 e 140 dias) e quatro repetições, sendo a parcela constituída por seis hastes porta-borbulhas. A viabilidade para enxertia das borbulhas da laranjeira ‘Baianinha' foi reduzida para 83,4\%, quando armazenadas por 120 dias, fato não observado para 'Pêra Rio’. A idade das hastes não influenciou a viabilidade das borbulhas da laranjeira ‘Baianinha’, enquanto para a ‘Pêra Rio’ ocorreu elevação de 91\% de viabilidade quando retiradas de hastes com 100 dias de idade e para 100\% de viabilidade para hastes de 140 dias. Para a laranjeira ‘Baianinha’ houve correlação positiva e significativa ( $r=0,78$; $\mathrm{p}<0,01)$ entre os teores de açúcares solúveis totais das hastes e o crescimento das brotações dos enxertos e entre a massa seca e os teores de amido das hastes $(r=0,94 ; \mathrm{p}<0,05)$.

Palavras-chave: Citrus sinensis (L.) Osbeck, viabilidade das borbulhas, carboidratos

\section{ABSTRACT}

\section{Effect of different storage periods on bud grafting viability of citrus bubsticks at different stages of development}

Citrus buds require special storage conditions in order to keep their viability for future grafting. The objective of this work was to evaluate the effect of different storage periods and different budstick ages on bud viability of two sweet orange cultivars. The experiments were arranged as a 2 x 3 x 3 factorial and set out in a randomized complete block design using two sweet orange cultivars ('Baianinha' and 'Pêra Rio'), three different storage periods (0, 60 and 120 days) and three different ages (100, 120 and 140 days) with four replications, with each plot consisting of six budsticks. Bud viability of orange cv. 'Baianinha' was reduced to $83.4 \%$ when stored for 120 days, however the storage period did not affect cv. 'Pêra Rio'. Budstick age had no influence on bud viability of cv. 'Baianinha', however, there was an increase in bud viability of cv. ‘Pêra Rio’ from 91\% (100 days old) to 100\% (140 days old). Positive and significant correlation $(r=0,78 ; p<0,01)$ between total soluble solids and grafted shoot growth, as well as dry matter and starch levels of budsticks ( $r=0,94 ; \mathrm{p}<0,05)$ occurred for cv. 'Baianinha'..

Key words: Citrus sinensis (L.) Osbeck, bud viability, carbohydrates

\footnotetext{
Recebido para publicação em agosto de 2008 e aprovado em junho de 2009

${ }^{1}$ Engenheiros-Agrônomos, Doutores. Programa de Pós-Graduação em Fitotecnia, Centro de Ciências Agrárias (CCA), Universidade Federal de Viçosa (UFV), Av. PH Rolfs, s/ n, 36570-000, Viçosa, Minas Gerais, Brasil. siqueira@ufv.br (autor para correspondência), lsalomao@ufv.br

${ }^{2}$ Engenheiro-Agrônomo, Doutor. Programa de Pós-Graduação em Estatística, CCA, UFV, Av. PH Rolfs, s/n, 36570-000, Viçosa, MG, Brasil. peternelli@ufv.br

${ }^{3}$ Engenheiro-Agrônomo, Mestre. Programa de Pós-Graduação em Fitotecnia, CCA, UFV, Av. PH Rolfs, s/n, 36570-000, Viçosa, MG, Brasil. dierlei@vicosa.ufv.br

${ }^{4}$ Engenheiro-Agrônomo, Mestre. Instituto Capixaba de Pesquisa, Assistência Técnica e Extensão Rural, Rua Afonso Sarlo, 160, 29052-010, Vitória, Espírito Santo, Brasil. ccastelo@incaper.es.gov.br
} 


\section{INTRODUÇÃO}

A enxertia por borbulhia em “T” invertido é o principal método usado para a propagação comercial dos citros. Por ser um método de propagação vegetativa, apresenta como principais vantagens a uniformidade de produção, qualidade dos frutos e precocidade para o início de produção (Sempionato et al., 1997).

As mudas com padrão de qualidade recomendado por pesquisadores e técnicos da área de citricultura são obtidas a partir de borbulhas retiradas de plantas matrizes registradas e/ou de borbulheiras protegidas, monitoradas para sua sanidade (Carvalho et al., 2005).

As borbulhas, por serem material perecível, requerem condições especiais de armazenamento para que, após determinado período de conservação, ainda mantenham sua viabilidade para a enxertia. O período compreendido entre a colheita das hastes porta-borbulhas até a enxertia pode ser longo, devido a vários fatores, como problemas no transporte, condições climáticas que desfavoreçam a enxertia, indisponibilidade de porta-enxertos no ponto de enxertia e necessidade de novas enxertias por falhas no pegamento do enxerto. Deve-se considerar ainda que a oferta de hastes porta-borbulhas é sazonal, pois as borbulhas possuem um ponto adequado de maturação para serem colhidas (Aubert \& Vullin, 1998; Romeiro et al., 2001).

O presente trabalho teve como objetivo estudar a manutenção da viabilidade das borbulhas e o crescimento das brotações de enxertos provenientes das hastes porta-borbulhas dos cultivares laranjeiras 'Baianinha' e 'Pêra Rio' de diferentes idades, submetidas a três períodos de armazenamento refrigerado.

\section{MATERIAL E MÉTODOS}

Foram utilizadas hastes porta-borbulhas de 21 plantas das laranjeiras 'Baianinha' e 'Pêra Rio'. As hastes foram coletadas na borbulheira da Universidade Federal de Viçosa, Viçosa, Minas Gerais, conduzida a céu aberto e em sistema adensado.

Utilizou-se o delineamento em blocos casualizados, com os tratamentos dispostos em esquema fatorial $2 \times 2 \mathrm{x}$ 3. Os fatores foram dois cultivares de laranjeira ('Baianinha' e 'Pêra Rio'), três períodos de armazenamento de hastes porta-borbulhas (0, 60 e 120 dias) e três idades das hastes (100, 120 e 140 dias), com quatro repetições. A parcela foi constituída por seis hastes.

As plantas foram podadas em três diferentes épocas, para permitir a coleta das hastes com diferentes idades $(100,120$ e 140 dias). As podas foram realizadas de $20 \mathrm{em}$ 20 dias, sendo a primeira executada no dia 17/04/2003, em sete plantas de cada cultivar, a segunda no dia 07/05/ 2003, em outras sete plantas, e a terceira, no dia 27/05/ 2003, nas últimas sete plantas.
A coleta foi efetuada aos 100 dias após a terceira poda (09/09/2003). Nesse momento, as hastes das plantas podadas no dia 27/05/2003 encontravam-se no estádio de desenvolvimento preferido pelos viveiristas da Zona da Mata Mineira (angulosas e tenras). Naquela data, as hastes das plantas que foram podadas nos dias 17/04/2003 e 07/05/2003 estavam com idades de 120 e 140 dias, respectivamente.

Após a coleta, as hastes foram separadas em grupos, de acordo com sua idade, e padronizadas de modo a conter em média 10 borbulhas. As folhas foram retiradas, conservando-se os pecíolos com $5 \mathrm{~mm}$ de comprimento, aproximadamente. Em seguida, foram agrupadas em feixes contendo seis hastes, cuja massa foi avaliada.

Imediatamente após, as hastes foram lavadas em água deionizada e desinfestadas por imersão em solução comercial de hipoclorito de sódio a $1 \%$ de cloro ativo, durante 15 minutos, e lavadas novamente em água deionizada. Em seguida, os feixes foram mergulhados, por 15 minutos, em uma solução de 2,4-D (ácido 2,4 diclorofenoxiacético), para fixação dos pecíolos, na dosagem de $20 \mu \mathrm{mol} \mathrm{L} \mathrm{L}^{-1}$ (Lima, 2001), em ambiente escuro, para evitar a degradação da auxina. Posteriormente, as hastes foram imersas por 15 minutos em solução com 1,0 g L Le de água de cada um dos fungicidas tiofanato metílico e captan. Após secagem à sombra, as pontas das hastes foram imersas por aproximadamente um segundo, em parafina comercial derretida a $76^{\circ} \mathrm{C}$, formando uma película de $1 \mathrm{~mm}$ de espessura (Silva \& Lopes, 1993).

Cada grupo de seis hastes foi então acondicionado em sacos de polietileno transparentes, de baixa densidade, com dimensões de $20 \mathrm{~cm}$ x $30 \mathrm{~cm}$ e $15 \mu \mathrm{m}$ de espessura. Após, foram armazenados em câmara fria à temperatura de $5 \pm 1{ }^{\circ} \mathrm{C}$ e umidade de $87,5 \pm 2,5 \%$, durante 60 e 120 dias. Após o término de cada um dos períodos, os feixes foram novamente pesados. Quatro hastes de cada tratamento foram utilizadas para as enxertias visando à avaliação da viabilidade e ao crescimento das brotações. Duas hastes foram secas em estufa a $75^{\circ} \mathrm{C}$ até peso constante, para cálculo do teor de umidade e análises dos teores de amido e açúcares.

Para testar a viabilidade das borbulhas e o crescimento das brotações, foram realizadas enxertias em plantas de limoeiro ‘Cravo' (Citrus limonia (L.) Osbeck) cultivadas em sacolas plásticas contendo cinco $\mathrm{dm}^{3}$ de substrato à base de casca de pinus e vermiculita, em condições de casa de vegetação. Esses porta-enxertos foram previamente semeados em tubetes de $50 \mathrm{~cm}^{3}$, em períodos diferentes, para estar com o diâmetro adequado na época da enxertia de cada tratamento de armazenamento (0, 60 e 120 dias).

As enxertias foram realizadas nos dias 09/09/03 (hastes não-armazenadas), 10/11/03 (hastes com 60 dias de 
armazenamento) e 12/01/04 (hastes com 120 dias de armazenamento). Foram retiradas duas borbulhas da parte mediana de cada haste, que foram enxertadas em $\mathrm{T}$ invertido em lados opostos de cada porta-enxerto, sendo a primeira enxertia realizada a $15 \mathrm{~cm}$ do nível do substrato e a outra a $20 \mathrm{~cm}$.

Avaliaram-se a massa seca das hastes, antes e após o armazenamento, os teores de amido e açúcares solúveis totais nas hastes armazenadas, a viabilidade das borbulhas (22 dia após a enxertia) e o crescimento das brotações (64 dias após a enxertia).

Para a determinação dos teores de amido e açúcares solúveis totais das hastes, as amostras foram secas em estufa de circulação forçada de ar, a $75{ }^{\circ} \mathrm{C}$, moídas e pesadas. Para a extração dos açúcares solúveis totais, as amostras foram centrifugadas com etanol $80 \%$. O resíduo obtido foi utilizado para a análise de amido. Os sobrenadantes obtidos foram evaporados até à secagem em evaporador rotativo a vácuo e o resíduo foi ressuspendido em $10 \mathrm{~mL}$ de água destilada e filtrado em papel de filtro Whatmann ${ }^{\circledR} n^{0} 2$.

Ao resíduo obtido para a análise de amido foram adicionados $10 \mathrm{~mL}$ de ácido perclórico 35\% em tubos de centrífuga, agitado e deixado repousar por 24 horas. Após, transferiu-se esse material para balão de $50 \mathrm{~mL}$, completando-se o volume e agitando-se a mistura, a qual foi filtrada utilizando-se papel de filtro Whatmann ${ }^{\circledR} n^{\circ} 2$. Desse extrato tomaram-se alíquotas para quantificação dos teores de carboidratos solúveis totais e amido, os quais foram determinados por meio das reações com antrona, conforme McCready et al. (1950).

A análise estatística foi feita com o auxílio do software livre “R” (R Development Core Team, 2003). Foi usado o método dos contrastes ortogonais, conforme apresentado por Pearce (1992), para a determinação do modelo ajustado na análise de superfície de resposta. O coeficiente de determinação $\left(\mathrm{R}^{2}\right)$ foi calculado pela razão entre a soma dos quadrados da regressão (SQReg.) e a soma dos quadrados de tratamentos (SQTrat.). Estudaram-se as correlações de Pearson entre as variáveis avaliadas (Steel \& Torrie, 1981).

\section{RESULTADOS E DISCUSSÃO \\ Observou-se aumento linear na viabilidade para enxertia das borbulhas do cultivar 'Pêra Rio’ de 91\% para aproxim adamente $100 \%$ com o aumento da idade das has- tes (Fig ura 1b). O maior percentual de pegamento da enxertid das borbulhas oriundas das hastes mais velhas pode se devido a sua maior lignificação, que reduz a perda d água e, consequentemente, aumenta o tempo de arma zenamento, além de possivelmente a maior quan- tidade de nutrientes armazenados nessas hastes. Ape-}

sar de não ter havido aumento na massa seca das hastes em função da idade (Figura 2h) e de haver tendência de aumento de lignificação com o tempo, independentemente da espécie, diferenças genotípicas são provavelmente responsáveis pelos diferentes padrões de lignificação entre os dois cultivares testados. Tais resultados diferem dos encontrados por Fontes et al. (1981), que não verificaram diferença no pegamento da enxertia de laranjeira 'Pêra Rio' usando borbulhas com diferentes graus de maturação, bem como não afetou a viabilidade das borbulhas da laranjeira 'Baianinha' no presente estudo (Figura 1a).

Uma redução em viabilidade das borbulhas de laranjeira ‘Baianinha' de 96,6 para 83,4\% foi observada com o aumento no período de armazenamento (Figura 1c). Essa perda de viabilidade pode estar relacionada aos processos metabólicos da respiração que continuam, mesmo após a colheita, induzindo ao desdobramento das substâncias de reservas. Embora essa atividade metabólica seja diminuída pela baixa temperatura ela não cessa, causando, consequentemente, redução na viabilidade das borbulhas à medida que há aumento do período de armazenamento (Bissoli, 1986). A redução na viabilidade das borbulhas de diferentes variedades foi também constatada por Cardoso (1961) e Souza et al. (1990), trabalhando com seringueira, e Bryson (1969), Teixeira (1969), Bissoli (1986), Carvalho (1998) e Siqueira et al. (2001), em citros. Para a 'Pêra Rio’ não foi verificado efeito significativo do armazenamento sobre a viabilidade das borbulhas (Figura 1d), embora tenha havido irregularidade no comportamento dessa característica ao longo do tempo. Hastes portaborbulhas de laranjeira 'Pêra' parecem tolerar maior período de armazenamento em relação à 'Baianinha', tendo Blumer (2000) considerado viável a conservação de borbulhas desse cultivar por 155 dias, acondicionadas em embalagem de polietileno, em temperatura média de $8^{\circ} \mathrm{C}$.

As brotações provenientes das enxertias feitas com borbulhas de hastes não-armazenadas foram maiores para a 'Baianinha $(18,1 \mathrm{~cm})$ do que para a 'Pêra Rio $(14,57 \mathrm{~cm})$ (Figuras 2a, c). A ocorrência de diferenças no desenvolvimento das brotações dos cultivares estudados se deve, provavelmente, a diferenças genotípicas, como também observado por Ramalho Sobrinho (1986) quando estudou brotações de laranjeira (Citrus sinensis (L.) Osbeck), tangerineira (Citrus reticulata Blanco) e limoeiro (Citrus limon (L.) Burm. f.).

Para ambos os cultivares, constatou-se que o comprimento das brotações dos enxertos foi maior para borbulhas de hastes não-armazenadas, embora um ligeiro aumento no comprimento das brotações tenha sido observado após 60 dias de armazenamento (Figuras 2a, c). Por outro lado, a idade das hastes não influenciou o comprimento das brotações dos enxertos das laranjei-

Rev. Ceres, Viçosa, v. 57, n.1, p. 103-111, jan/fev, 2010 

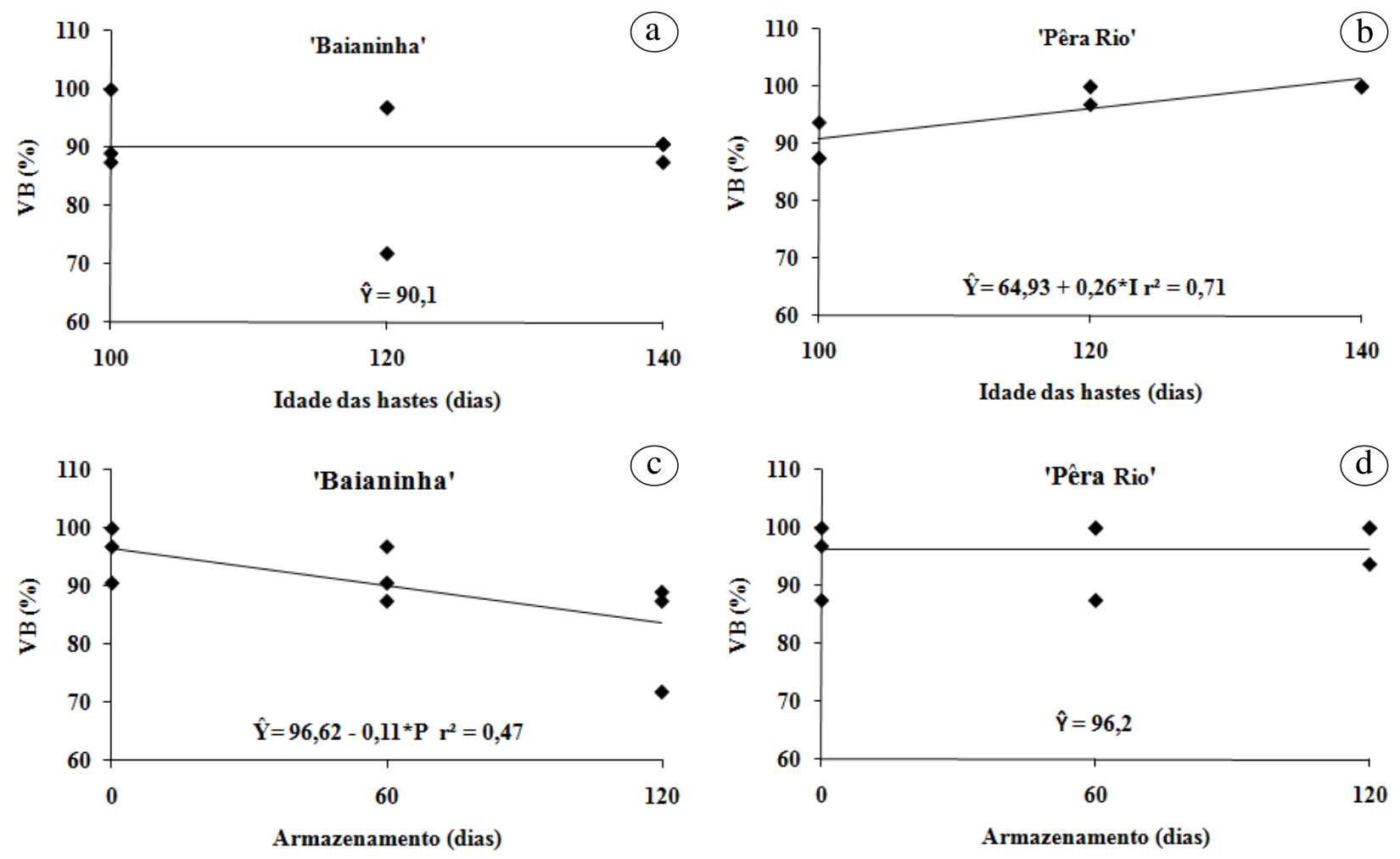

Figura 1. Estimativa da viabilidade das borbulhas (VB) das laranjeiras 'Baianinha' e 'Pêra Rio' em função da idade das hastes (a e b) e do período de armazenamento (c e d).

ras ‘Baianinha’ e ‘Pêra Rio’. Esses resultados são diferentes daqueles relatados por Teixeira (1969), que não verificou diferença no desenvolvimento de enxertos da laranjeira 'Natal', independentemente do período de conservação das hastes porta-borbulhas (0, 4, 8, 12, 16 e 20 dias). Destaca-se que na pesquisa desse autor, o período máximo de armazenamento foi de apenas 20 dias, enquanto neste trabalho as hastes foram estocadas por 60 ou 120 dias, ou seja, se um período maior de estocagem tivesse sido testado pelo autor, possível perda em viabilidade poderia ter sido observada em comparação ao tratamento controle (borbulhas de hastes não submetidas ao armazenamento). Siqueira et al. (2001) também não encontraram efeito significativo do tempo de conservação (60 dias) sobre o comprimento das brotações para a laranjeira 'Baía', enquanto para 'Serra-d’Água' verificaram que o comprimento foi maior até o tempo de conservação estimado de 43 dias, diminuindo com maiores tempos de conservação (de 43 a 60 dias). Verifica-se muita discrepância de resultados entre diferentes autores quanto ao crescimento de brotações em enxertos em função do tempo de armazenamento. Tais discrepâncias podem ser ocasionadas por diferentes condições de execução dos trabalhos, como clima, substrato de cultivo, cultivares copa e porta-enxertos, manejo das plantas, pragas, doenças, entre outros.
Para ambos os cultivares de laranjeira, não houve influência do período de armazenamento nem da idade das hastes sobre a massa seca (Figuras 2e, f, g e h), diferentemente de Maciel et al. (2008), que observaram redução de 21,1\% no teor de substâncias de reserva dos ramos portaborbulhas da tangerineira 'Montenegrina' armazenados por um período de 90 dias, em ambiente refrigerado.

Com o aumento do período de armazenamento, observaram-se queda no teor de açúcares solúveis totais (AST), independentemente da idade das hastes, para ambas as laranjeiras (Figuras 3a, c). Maiores teores de açúcares solúveis totais (AST) podem estar relacionados aos maiores comprimentos das brotações cujas borbulhas foram provenientes das hastes que não sofreram armazenamento em relação às armazenadas (Figuras 2a, c e 3a, c). Entretanto, não é possível afirmar com segurança que exista uma relação causa-efeito entre essas duas características, considerando-se que a mesma tendência não foi observada nas hastes armazenadas por períodos maiores e que outros fatores podem interferir nos resultados.

Para a laranjeira 'Baianinha', os menores teores foram verificados nas hastes colhidas aos 100 dias após a poda em relação ao armazenamento (38\%) (Figura 3a). Os maiores teores foram observados nas hastes sem armazenamento e colhidas com 120 dias de idade (8,1\%) (Figuras 3a, b). Esse fato parece estar relacionado ao consumo de açúcares devido a sua utilização no proces- 
so respiratório das hastes (Kozlowski, 1992), que foi maior naquelas com idade de 100 dias, por terem menores reservas acumuladas do que as hastes colhidas aos 120 e 140 dias.

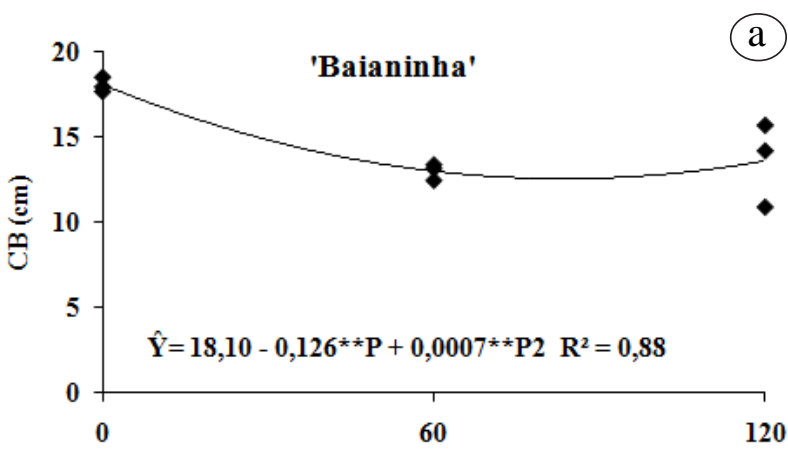

Armazenamento (dias)

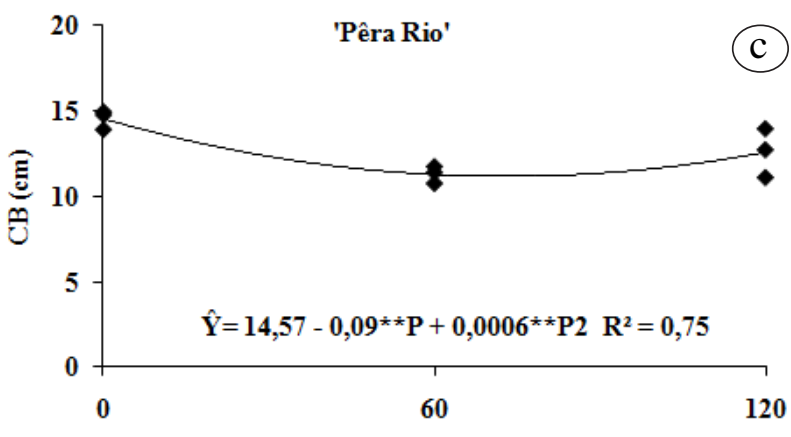

Armazenamento (dias)

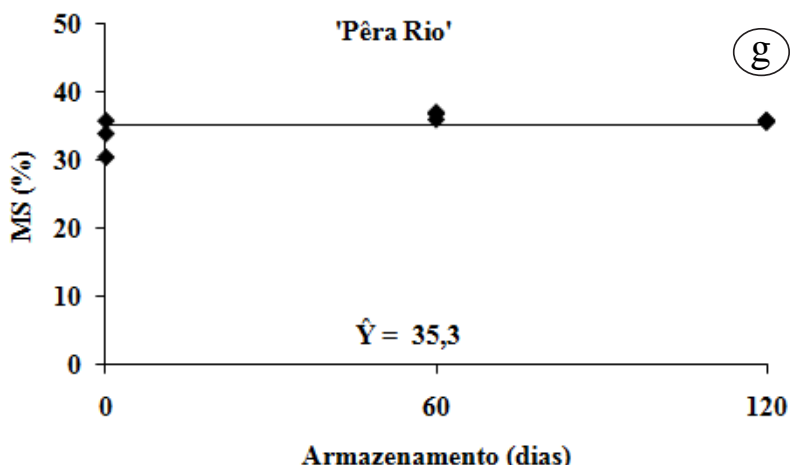

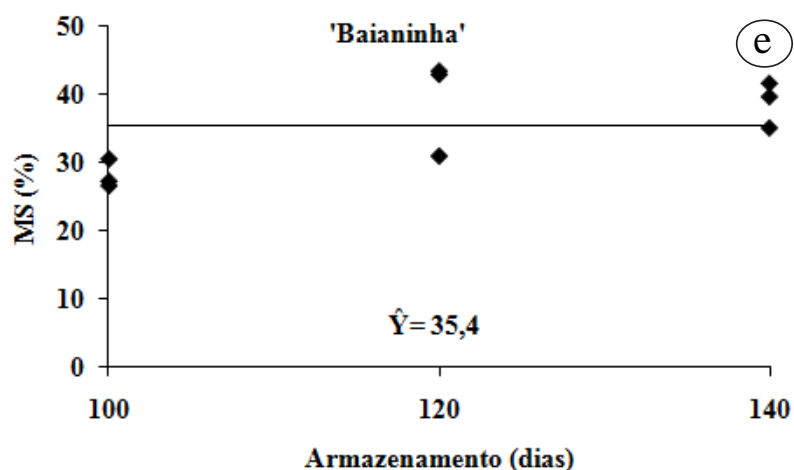

Para a 'Pêra Rio', não houve alteração nos teores de açúcares solúveis totais em função da idade das hastes (Figura 3d). O decréscimo nos teores de açúcares com o aumento do armazenamento variou de 6,3\% para as has-
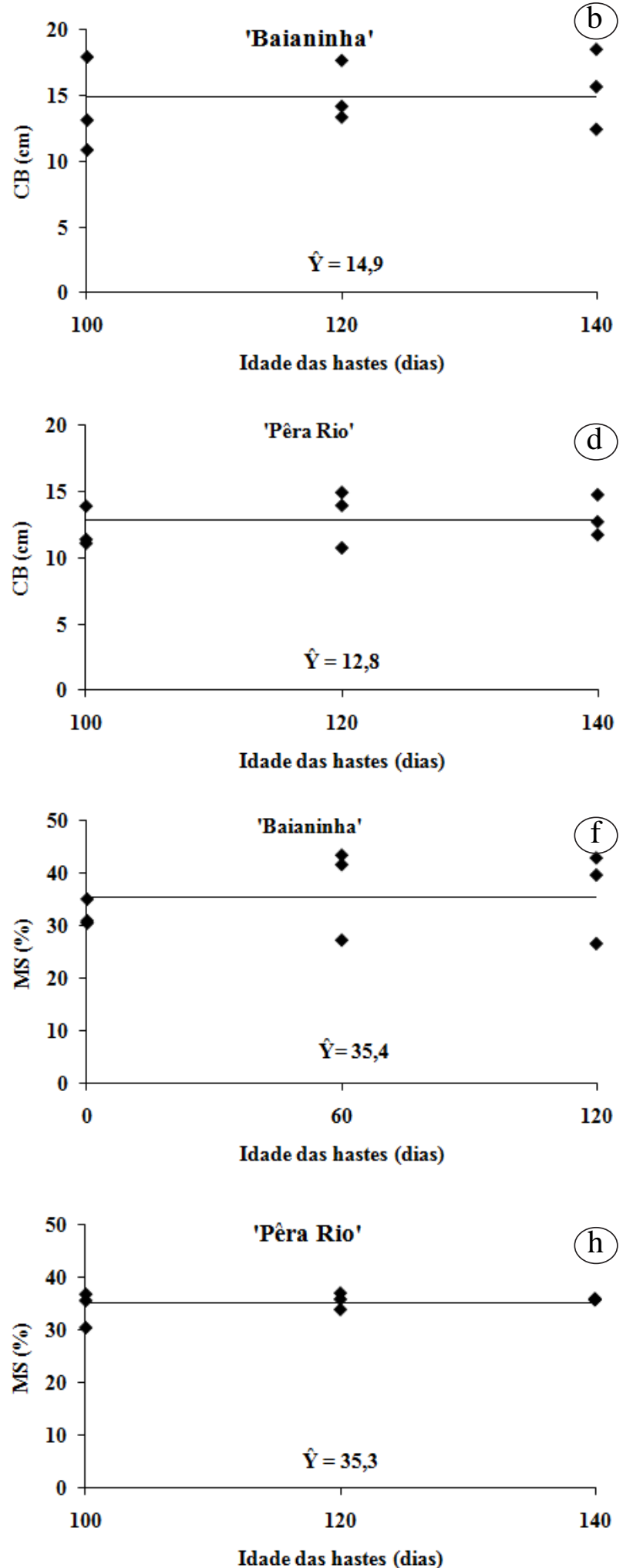

Figura 2. Massa seca (MS) das hastes porta-borbulhas e Crescimento das brotações (CB) das laranjeiras 'Baianinha’ e Pêra Rio', em função da idade das hastes (b, d, f e h) e do período de armazenamento (a, c, e e g). 
tes que não foram armazenadas a 3,0\% para aquelas armazenadas por 120 dias (Figura 3c).

Os maiores teores de amido para a laranjeira 'Baianinha' ocorreram nas hastes com idade de 120 e 140 dias e armazenadas por 60 dias (9,3\%) (Figuras 4a, b). Os menores foram observados nas hastes armazenadas por 120 dias e colhidas com 100 dias (5,0\%) (Figura 4b). Para a 'Pêra Rio, observou-se maior acúmulo de amido nas hastes maduras, mas independentemente da idade houve queda desses teores com o aumento do período de armazenamento. Os maiores teores ocorreram nas hastes não armazenadas com idade de 140 dias (56\%), e menor para aquelas com idade de 100 dias armazenadas por 120 dias (12\%) (Figuras 4c, d). Esses resultados podem estar relacionados com a utilização de carboidratos de reserva pelas hastes, com a finalidade de sintetizar açúcares solúveis para a proteção dos tecidos contra as baixas temperaturas da câmara fria (Kozlowski, 1992; Kramer \& Kozlowski, 1979; Stieckman \& Boe, 1978; Wong et al., 2003) e com a pouca idade da haste (100 dias), insuficiente para acumular amido, se comparado aos demais tratamentos.

Quando o processo de união dos tecidos é mais rápido, as conexões do córtex, cilindro central e feixes vasculares também são estabelecidas mais rapidamente, permitindo a passagem do fluxo de transpiração e de materiais nutritivos provenientes do porta-enxerto para a borbulha, favorecendo o desenvolvimento do enxerto
(Shimoya et al., 1968; Hartmann et al., 1997; Gomes et al., 2002). Para a laranjeira 'Baianinha', houve correlação positiva e significativa $(r=0,78 ; p<0,01)$ entre os teores de açúcares solúveis totais das hastes e o crescimento das brotações (Tabela 1). É possível que as hastes e, consequentemente, as borbulhas, que possuem maiores teores de açúcares, possam suprir, de forma mais eficiente, a demanda por carboidratos resultantes do processo de cicatrização e união dos tecidos enxertados. Também houve correlação positiva $(r=0,94$; $p<0,05)$ entre a massa seca e os teores de amido nas hastes porta-borbulhas para a 'Baianinha' (Tabela 1). Segundo Larcher (2000), as plantas são constituídas em grande parte por carboidratos, sendo essas substâncias responsáveis por $60 \%$ ou mais da massa seca vegetal, por isso quanto maior for o teor de amido maior será a massa seca de determinado órgão vegetal.

Para a 'Pêra Rio', foi encontrada correlação negativa da massa seca com os teores de açúcares solúveis totais (Tabela 2). Uma das possíveis explicações para o fato seria a conversão do amido em açúcares solúveis, aumentando sua concentração. Por sua vez, esses açúcares seriam usados na respiração, provocando maior consumo de amido e, consequentemente, redução da massa seca.

Não foram verificadas correlações significativas entre viabilidade das borbulhas e comprimento das brotações,
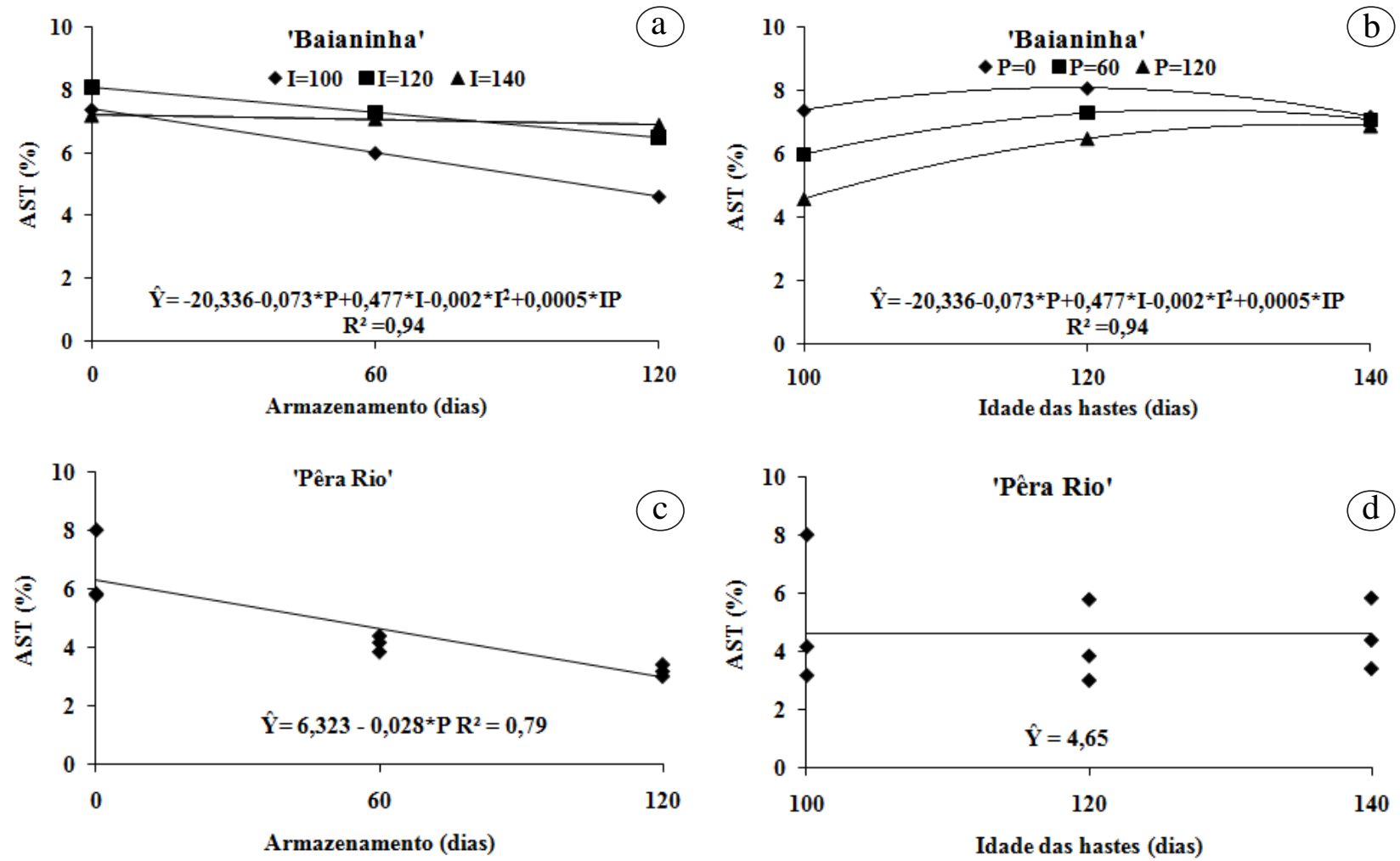

Figura 3. Estimativas dos teores de açúcares solúveis totais (AST) das hastes porta-borbulhas das laranjeiras ‘Baianinha’ e 'Pêra Rio’ em função da idade das hastes (b e d) e do armazenamento (a e c).

Rev. Ceres, Viçosa, v. 57, n.1, p. 103-111, jan/fev, 2010 

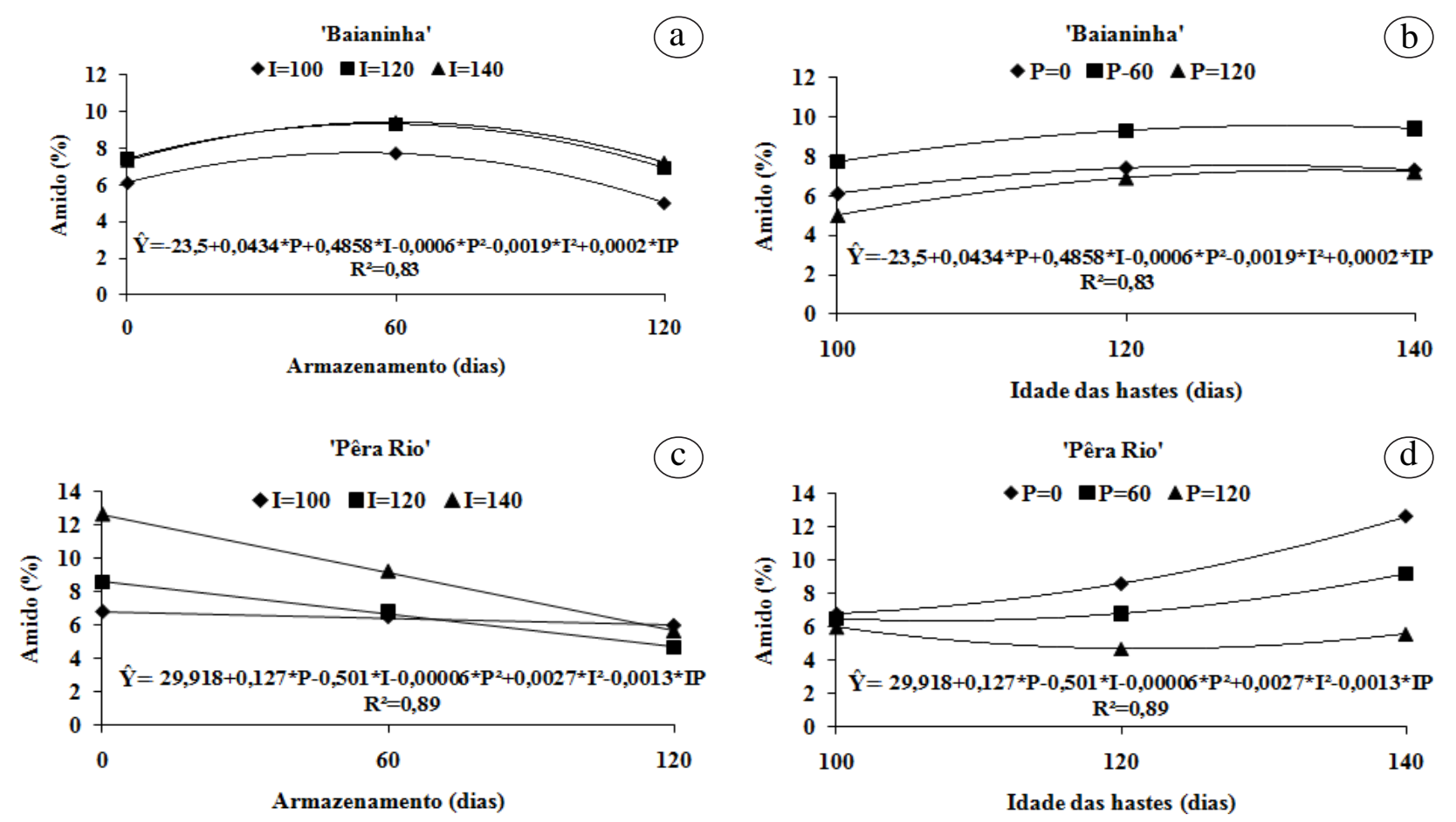

Figura 4. Estimativas dos teores de amido das hastes porta-borbulhas das laranjeiras 'Baianinha' e 'Pêra Rio' em função do armazenamento (a e c) e idade das hastes (b e d).

Tabela 1. Correlações lineares simples entre viabilidade das borbulhas (VB), crescimento das brotações (CB), matéria seca (MS), açúcares solúveis totais (AST) e amido, da laranjeira ‘Baianinha’. Viçosa, MG, 2004

\begin{tabular}{lccccc}
\hline Variáveis & VB & CB & MS & AST & Amido \\
\hline VB & - & $0,36^{\text {ns }}$ & $-0,31^{\text {ns }}$ & $0,51^{\text {ns }}$ & $0,12^{\text {ns }}$ \\
CB & - & - & $-0,11^{\text {ns }}$ & $0,78^{* *}$ & $0,05^{\text {ns }}$ \\
MS & - & - & - & $0,11^{\text {ns }}$ & $0,71^{*}$ \\
AST & - & - & - & - & $0,37^{\text {ns }}$ \\
Amido & - & - & - & - & - \\
\hline
\end{tabular}

ns = não-significativo; ${ }^{*}$ e $* *$ = significativo, a 5 e $1 \%$ de probabilidade, respectivamente, pelo teste t.

Tabela 2. Correlações lineares simples entre viabilidade das borbulhas (VB), crescimento das brotações (CB), matéria seca (MS), açúcares solúveis totais (AST) e amido, da laranjeira 'Pêra Rio'. Viçosa, MG, 2004

\begin{tabular}{lccccc}
\hline Variáveis & VB & CB & MS & AST & Amido \\
\hline VB & - & $0,11^{\text {ns }}$ & $0,51^{\text {ns }}$ & $-0,44^{\text {ns }}$ & $0,14^{\text {ns }}$ \\
CB & - & - & $-0,54^{\text {ns }}$ & $0,55^{\mathrm{ns}}$ & $0,44^{\text {ns }}$ \\
MS & - & - & - & $-0,81^{* *}$ & $0,05^{\text {ns }}$ \\
AST & - & - & - & - & $0,46^{\text {ns }}$ \\
Amido & - & - & - & - & - \\
\hline
\end{tabular}

ns = não-significativo; * $\mathrm{e}^{* *}=$ significativo, a 5 e $1 \%$ de probabilidade, respectivamente, pelo teste $\mathrm{t}$.

massa seca das hastes, teores de açúcares solúveis totais e amido para os dois cultivares estudados (Tabelas 1 e 2). Araújo (1999), em estudo com umbuzeiro (Spondias tuberosa Arruda), também não verificou relação entre conteúdo de açúcares totais (extraídos dos garfos e dos porta-enxertos por ocasião de cada enxertia) e índice de pegamento de enxerto e sugeriu que a quantidade mínima de açúcares totais encontrada ao longo das amostragens de cada enxertia foi suficiente para promover um índice satisfatório de pegamento do enxerto.
Pesquisas como a de Araújo (1999) sobre o efeito dos teores de carboidratos em garfos ou borbulhas e sua influência sobre o sucesso da enxertia são escassas. No caso da borbulhia de citros, os resultados obtidos não indicaram uma relação clara entre teores de carboidratos nas hastes e viabilidade da enxertia e crescimento das brotações. As possíveis explicações para esse fato são várias, uma delas seria a ausência de aplicação de tratamentos que aumentam os teores de carboidratos nas hastes (Salisbury \& Ross, 1996). 
O tamanho reduzido das borbulhas usadas na enxertia de citros possivelmente contribui para que as reservas de carboidratos nelas contidas sejam pequenas, portanto insuficientes para influenciar o pegamento da enxertia e o crescimento posterior do enxerto. Além disso, o início da brotação do enxerto em citros é muito rápido (10 dias) (Santos et al., 2009), por isso imagina-se que as reservas contidas na borbulha tenham pouco efeito na viabilidade da enxertia, pois rapidamente ocorre a união dos tecidos e restabelecimento do fluxo de seiva.

\section{CONCLUSÕES}

O aumento do período de armazenamento reduz a viabilidade das borbulhas do cultivar 'Baianinha', sem efeito para o 'Pêra Rio'.

Não há efeito da idade das hastes na viabilidade das borbulhas do cultivar 'Baianinha', porém para o 'Pêra Rio' há aumento linear da viabilidade à medida que aumenta a maturidade das hastes.

A idade das hastes não influencia o crescimento das brotações dos cultivares 'Baianinha' e 'Pêra Rio', entretanto ele é maior quando as borbulhas utilizadas para a enxertia são retiradas de hastes não submetidas ao armazenamento.

Há variações nos teores de açúcares solúveis totais e de amido nas hastes nos diferentes períodos de armazenamento e idades, mas, de forma geral, elas não são úteis para explicar as diferenças encontradas na viabilidade das borbulhas e no crescimento das brotações.

\section{REFERÊNCIAS}

Araújo FP (1999) Métodos de enxertia na propagação do umbuzeiro (Spondias tuberosa Arr. Cam.) em diferentes épocas do ano. Tese de Mestrado. Escola de Agronomia, Universidade Federal da Bahia, Cruz das Almas, 71p.

Aubert B \& Vullin G (1998) Citrus nurseries and planting techniques. Montpellier, Cirad. 183p.

Bissoli MJAC (1986) Estudo da conservação de borbulhas de quatro espécies cítricas (Citrus spp.) empregando diferentes processos de desinfecção. Tese de Mestrado. Escola Superior de Agricultura “Luiz de Queiroz”, Piracicaba, 61p.

Blumer S (2000) Efeitos de revestimento e acondicionamentos em baixa temperatura na preservação pós-colheita de ramos porta-borbulhas de laranjeira 'Pêra' (Citrus sinensis (L.) Osbeck). Tese de Mestrado. Escola Superior de Agricultura "Luiz de Queiroz”, Piracicaba, 54p.

Bryson RSO (1969) Efeito do grau de maturação e do período de armazenamento das borbulha, no rendimento da enxertia, em Citrus sinensis. Dissertação de Mestrado, Universidade Federal de Viçosa, Viçosa, 35p.

Cardoso M (1961) Conservação de hastes de seringueira destinadas à enxertia. Bragantia, 20:63-66.
Carvalho SA, Graf CC \& Violante, AR (2005) Produção de material básico e propagação. In: Mattos DJr, De Negri JD, Pio RM \& Pompeu JJr. (Eds.) Citros. Campinas, Instituto Agronômico e Fundag. p.279-316.

Carvalho SA (1998) Estratégias para estabelecimento e manutenção de matrizes, borbulheiras e viveiro de citros em ambiente protegido. In: $5^{\circ}$ Seminário Internacional de Citros - Tratos Culturais, Bebedouro. Anais, Fundação Cargill. p.67-101.

Fontes HR, Trindade J \& Vieira G (1981) Influência do acondicionamento, período de armazenamento e grau de maturação de borbulhas, no pegamento da enxertia de laranjeira 'Pêra' (Citrus sinensis (L.) Osbeck). In: $1^{\circ}$ Seminário de Pesquisas Agropecuárias de Sergipe, Aracaju. Anais, Estação Experimental de Boquim. p.41-45.

Gomes GA, Paiva R, Santana JRF, Paiva PDO \& Chalfun NNJ (2002) Propagação de espécies lenhosas. Informe Agropecuário, 23:12-15.

Hartmann HT, Kester DE, Davies Jr. FT (1997) Plant propagation: principles and practices. 6 ed. New Jersey, Prentice Hall. 770p.

Kozlowski TT (1992) Carbohydrate sources and sinks in woody plants. The Botanical Review, 58:107-222.

Kramer PJ \& Kozlowski TT (1979) Environmental and cultural factors affecting growth. In: Kramer PJ \& Kozlowski TT (Eds.) Physiology of woody plants. San Diego, Academic Press. p.645665.

Larcher W (2000) Ecofisiologia vegetal. In: Assis Prado CHB (Trad.) São Carlos, Rima Artes e Textos. 531p.

Lima SFF (2001) Conservação pós-colheita de hastes porta-borbulhas de citros armazenadas em baixa temperatura e tratadas

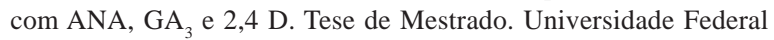
de Viçosa, Viçosa, 58p.

Maciel HS, Souza PVD \& Schäfer G (2008) Viabilidade de borbulhas de citros coletadas de ambiente protegido e mantidas em frigoconservação. Revista Brasileira de Fruticultura, 30:241-245.

McCready RM, Guggolz, J, Silviera V \& Owens HS (1950) Determination of starch and amylose in vegetables. Application to peas. Analytical Chemistry, 22:1156-1158.

Pearce SC (1992) Data analysis in agricultural experimentation. II. Some standard contrasts. Experimental Agriculture, 28:375383.

R Development Core Team (2003) R: A Language and Environment for Statistical Computing. Vienna: R Foundation for Statistical Computing, URL:http://www.R-Project.org.

Ramalho Sobrinho R (1986) Caracterização do surto de desenvolvimento primaveril em três espécies de citros. Tese de Mestrado. Escola Superior de Agricultura de Lavras, Lavras, 106p.

Romeiro S, Carvalho AS, Aguilar-Vildoso CI \& Blumer S (2001) Embalagem e tratamento químico na conservação de ramos porta-borbulhas de laranjeira 'Natal' em câmara fria. Laranja, 22:425-433.

Santos D, Siqueira DL, Borba AN \& Lelis FMV (2009) Proteção da gema e épocas de forçamento da brotação na enxertia da lima ácida Tahiti. Ciência e Agrotecnologia, 33:807-813.

Salisbury FB \& Ross CW (1996) Fisiologia vegetal. México, Grupo Editorial Iberoamérica. 759p.

Sempionato OR, Stuchi ES \& Donadio LC (1997) Viveiro de citros. Jaboticabal, Funep. 47p. (Boletim Citrícola, 2).

Shimoya C, Gomide CJ \& Fortes JM (1968) Estudo anatômico da enxertia em Citrus spp. Revista Ceres, 15:95-120.

Silva JBC \& Lopes CA (1993) Uso de parafina na conservação de ramas de batata doce. Horticultura Brasileira, 11:25-27. 
Siqueira DL, Pereira WE, Salomão LCC \& Furtado AL (2001) Pegamento e crescimento de enxertos de cinco variedades de citros em função de cinco períodos de armazenamento de hastes de borbulhas. Revista Brasileira de Fruticultura, 23:209-211.

Souza LH, Ventorim N, Oliveira LEM \& Soares AR (1990) Armazenamento de hastes de seringueira (Hevea brasiliensis Muell \& Arg.) 'Clone RRIM 600'. I. Efeito dos métodos de armazenamento sobre o índice de pegamento da enxertia. Revista Árvore, 14:69-77.

Stieckman S \& Boe AA (1978) Low temperature increases reducing and total sugar concentrations in leaves of boxwood (Buxus sempervirens L.) and Cranberry (Vaccinium macrocarpon Ait.). Hort Science, 13:439-440.
Steel RG \& Torrie JH (1981) Principles and procedures of statistics: a biometrical approach. 2th ed. Singapore, McGraw-Hill. 633p.

Teixeira SL (1969) Influência do período pós-colheita das hastes de citros, sobre a qualidade das borbulhas para a enxertia. Tese de Mestrado. Universidade Federal de Viçosa, Viçosa, 30p.

Wong BL, Bagget KL \& Rye AH (2003) Seasonal patterns of reserve and soluble carbohydrates in mature sugar maple (Acer saccharum). Canadian Journal of Botany, 81:780-788. 